Case Report The index is a 2.5 year old girl with moderate eczema associated with nocturnal itch. She was referred to local services and was trialled on topical Clobetasone and Betamethasone cream. After little improvement this was changed to topical Hydrocortisone (1\%) and Betamethasone cream. Her parents applied the steroid creams on a continuous basis for at least four months. They also sourced different homeopathic medicines from Pakistan. Upon analysis of their ingredients in the laboratory, Betamethasone and Dexamethasone were identified in one of them. She required a 5 day course of oral Prednisolone for an allergic reaction to nuts. Over time the eczema remitted but all treatments were continued. After six months, she presented with rapid weight gain over a 2 month period [weight $>98^{\text {th }}$ centile]. This was associated with increased skin pigmentation over ankles and knees, striae over her thighs and marked hypertrichosis.

Biochemical testing confirmed absence of diurnal variation with suppressed $8 \mathrm{am}$ cortisol levels. She was switched to maintenance eczema care with emollients and topical Tacrolimus. An ACTH stimulation test confirmed adrenal suppression [peak Cortisol $45 \mathrm{nmol} / \mathrm{L}$ ]. Adjunctive investigations for other causes of hypoadrenalism were reported normal. We educated the family on emergency management of cortisol deficiency and prescribed steroid replacement for emergency use only. After four weeks off all steroid containing medications, a repeat ACTH stimulation test confirmed normalisation of adrenal function [peak Cortisol $550 \mathrm{nmol} / \mathrm{L}$ ]. Four months later, her weight has normalised $\left[75-91^{\text {st }}\right.$ centile] and her eczema has remained under control. The pigmentation and striae have faded and her hypertrichosis is no longer evident.

Discussion The role of corticosteroids in the management of inflammation is well established but has resulted in widespread, prolonged and often unsupervised use. There is interindividual variation in steroid sensitivity, small doses can result in dramatic adverse effects. We did suspect that the homeopathic medicine was steroid based. This does not out-rule the possibility that the other ingredients facilitated steroid increased absorption or reduced metabolism.

Conclusion Adrenal suppression is a rare side effect of topical steroid use. Children on courses of steroids for longer than one week require medical monitoring to ensure that the treatment is appropriate, safe and used correctly.

\section{P289 METABOLIC COMPLICATIONS OF OBESITY IN CHILDREN}

Irina Osokina*. Science Centre of the Siberian Branch of Russian Academy of Science, Institute for Medical Studies of the North, Krasnoyarsk, Russian Federation

10.1136/archdischild-2019-epa.639

Introduction Children with obesity have high risk of metabolic complications.

Aim To reveal frequency of metabolic complications in children with obesity.

Methods We examined 91 obese children, aged 7-17 (BMI > 95 percentile). Mean age of children was $12.46 \pm 3.5$ yrs. Obesity in children manifested at $5.3 \pm 0.5$ yrs. Family anamnesis characterized by obesity in $71 \%$, diabetes type 2 - in $25 \%$, hypertension - in $53 \%$ in the first degree relatives. All patients were examined by clinical, biochemical, ultrasound methods. An oral glucose tolerance test (OGTT) accompanied by four point of insulinemia was performed. HOMA index was calculated according to the standard formula. In children with fatty liver chronic hepatitis were excluded. Metabolic syndrome (MS) was diagnosed according to a classical definition (Weiss's criteria).

Results In obese children metabolic complications were found in $39.6 \%$. The prevalence of the metabolic complications was follows: hypertriglyceridemia 38.2\%, glucose intolerance $17.6 \%$, hypertension $52.6 \%$. Increase of serum cholesterol was revealed in 24\%, low density lipoproteins - in 14\%, decrease of high-density lipoproteins - in 32\% children. Metabolic syndrome was found in 18 (19.8\%) patients with BMI $30.9 \pm$ $3.4 \mathrm{~kg} / \mathrm{m}^{2}$. Insulin resistance revealed in $25 \%$ children. HOMA index was $4.6 \pm 3.3 \mathrm{mIU} / \mathrm{l}$. Ultrasound signs of fatty liver were shown in 40 patients.

Conclusions This study showed a high prevalence of metabolic complications among obese schoolchildren.

\section{P290 POSSIBILITIES OF GENETIC RESEARCH IN THE PREVENTION OF THE DEVELOPMENT OF EXCESS MASS OF THE BODY AND OBESITY IN CHILDREN}

${ }^{1}$ Elena Bulatova, ${ }^{1}$ Olga Lagno, ${ }^{1}$ Alexander Shabalov*, ${ }^{2}$ Valeriy Polunovskiy, ${ }^{2}$ Ludmila Seledtsova. ${ }^{1}$ St. Petersburg State Pediatric Medical University, St. Petersburg, Russian Federation; ${ }^{2}$ LLC Natsionalnyiy Tsentr Geneticheskih Issledovaniy, Novosibirsk, Russian Federation

\subsection{6/archdischild-2019-epa.640}

Relevance Conducting genetic research in pediatric practice can help to create personalized dietary and therapeutic recommendations, as well as the implementation of appropriate physical activity.

Objective To determine the presence of polymorphisms of genes that contribute to the development of excess fat mass, increase the speed of carbohydrate absorption in patients with overweight and obesity to create further personalized recommendations on diet therapy and physical activity.

Patients and methods Surveyed 9 children ( 3 boys and 6 girls) aged from 6 to 10 years. Anamnesis was collected, an objective examination of patients, a biochemical examination of blood (lipidogram, fasting glucose), and a hormonal examination (insulin, TSH) were performed. All children underwent genetic screening based on DNA analysis (material - buccal epithelium) with the definition of gene polymorphisms: the FABP2 gene, which regulates the rate of fat absorption; PPARG gene, affecting the growth rate of fat cells; gene ADRB2, affecting the rate of carbohydrate consumption in the blood during exercise; The TCF7L2 gene, which regulates insulin secretion rate when glucose is released.

Results 4 patients were overweight, grade 1 obesity - 2;2 degrees - 2; Grade 3 obesity - 1 child. In all nine patients, unfavorable gene polymorphisms were found, contributing to impaired fat metabolism. In 5 children, according to DNA analysis, a reduced rate of consumption of carbohydrate reserves in response to an increase in the level of adrenaline in the blood was noted. 4 children showed a genetic predisposition to a decrease in the rate of insulin secretion in response to glucose intake. In a 3rd degree obese patient, all the studied gene polymorphisms that adversely affect carbohydrate and fat metabolism were found.

Conclusion All patients showed a genetic predisposition to impaired metabolism of fats and/or carbohydrates. Grade 3 obesity is associated with all modifications of genes that adversely affect both carbohydrate and fat metabolism, and 